\title{
O GRUPO DE IDOSOS DO POSTO DE SAÚDE DA VILA JARDIM: CONSIDERAÇÕES SOBRE ENVELHECIMENTO, MEMÓRIA E SOCIABILIDADE NO CONTEXTO DAS POLÍTICAS DE SAÚDE
}

\author{
Monalisa Dias de Siqueira ${ }^{1}$
}

Em meados de 2010 iniciei uma pesquisa etnográfica com um grupo de mulheres e homens idosos que se reúnem todas as sextas-feiras pela manhã na Unidade de Saúde Barão de Bagé, no bairro Vila Jardim, em Porto Alegre - RS. Os encontros tiveram início há mais de dez anos, a partir da solicitação dos idosos de um espaço para encontros e lazer. Atualmente, pode-se dizer que as atividades do grupo de idosos estão organizadas de acordo com as diretrizes do programa de "Promoção do Envelhecimento Saudável" propostas pelo Ministério da Saúde $^{2}$ e pelo Grupo Hospitalar Conceição ${ }^{3}$, o qual a unidade de saúde referida faz parte. Os encontros são mediados pela equipe de saúde da unidade (enfermeira, assistente social, estagiários de nutrição e agentes comunitárias de saúde) e tem como objetivo discutir as questões de saúde nessa fase da vida e também possibilitar a sociabilidade entre os participantes.

Os moradores da Vila Jardim tem uma trajetória de mobilização juntamente com a unidade de saúde do bairro e, ao longo dos anos, algumas das reivindicações foram atendidas pelos órgãos públicos (Giacomazzi, 1997). As mobilizações partiram, em geral, das mulheres, e entre as conquistas estão a criação da própria sede da unidade de saúde e de um centro comunitário que funciona em suas dependências.

Esse centro comunitário recebe o nome de uma das mais atuantes mulheres da comunidade: a Vovó Nair. Durante os encontros do grupo de idosos são constantes as lembranças com relação à sua perseverança, determinação e luta em benefício da comunidade. As lembranças referentes à sua trajetória de luta ficaram mais recorrentes nos últimos meses por conta do diagnóstico da Doença de Alzheimer (DA) ${ }^{4}$. De acordo

\footnotetext{
${ }^{1}$ Universidade Federal do Rio Grande do Sul, Brasil.

2 Em 2006, o SUS cria o PACTO PELA SAÚDE 2006 que busca enfatizar as necessidades de saúde da população e, para isso, divide-se em três componentes: Pacto pela Vida, Pacto em Defesa do SUS e Pacto de gestão do SUS. As prioridades do Pacto pela Vida são: Saúde do Idoso, Câncer de Colo de Útero e Mama, Mortalidade Infantil e Materna, Doenças Emergentes e Endemias, Promoção da Saúde, Atenção Básica a Saúde. Os objetivos das ações voltadas para a Saúde do Idoso dizem respeito à implantação da Política Nacional de Saúde da Pessoa Idosa, buscando a atenção integral. O programa de "Promoção do Envelhecimento Saudável" referido acima está incluído nesse contexto.

${ }^{3}$ O Grupo Hospitalar Conceição (GHC) é formado pelos hospitais Conceição, Criança Conceição, Cristo Redentor e Fêmina e mais 12 postos do Serviço de Saúde Comunitária.

${ }^{4}$ De acordo com o Ministério da Saúde, a Doença de Alzheimer - principal causa de demência entre idosos - é uma doença neurodegenerativa progressiva e irreversível de aparecimento insidioso, na qual ocorre perda de memória e deterioração progressiva de funções cognitivas como linguagem (afasia),
} 
com os relatos dos profissionais de saúde que acompanham o grupo e dos amigos mais próximos de Vovó Nair, a doença comprometeu sua saúde principalmente com relação à perda de memória, inicialmente observada pela progressiva desorientação de tempo e espaço e depois pelo agravamento dos outros sintomas.

As narrativas de enfrentamento de doença, dor, morte, vulnerabilidade, solidão e de problemas familiares são trazidas constantemente pelos participantes do grupo. A experiência de Nair com a DA, a sua progressiva perda de memória e, conseqüentemente, o afastamento de si mesma e do mundo mobilizou uma série de narrativas dos participantes do grupo sobre as lutas por melhorias sociais no bairro, o papel de liderança assumido por Nair, a participação dos moradores na construção do "posto" e o sentimento de pertencimento nesse contexto.

Assim, lembrar como "Vovó Nair era" e "tudo que ela fez" pelos moradores da Vila Jardim é uma forma dos idosos elaborarem juntamente com o grupo as diversas perdas e lidarem com as doenças atribuídas a essa fase da vida, ao mesmo tempo em que ressignificam a relação com os amigos, os familiares e os lugares. As experiências vividas e rememoradas por cada um deles relacionam-se com a construção de si mesmo e de seu lugar no mundo social, pois como sugere Halbwachs (2006), toda memória é, por definição, coletiva. A sociabilidade proporcionada pelos encontros semanais torna possível que os idosos narrem acontecimentos do presente, suas trajetórias de vida e que, de alguma forma, elaborem projetos para o futuro.

Desse modo, a partir da minha participação semanal nos encontros do grupo e em conversas individuais com alguns participantes (tanto idosos quanto profissionais de saúde do posto), pretendo refletir neste artigo sobre a proposta de envelhecimento "ativo" e "saudável" - que tem como objetivo principal a manutenção da "autonomia", da "independência" e da "qualidade de vida" -, bem como discutir questões relacionadas à sociabilidade e memória.

\footnotetext{
habilidades motoras (apraxias) e percepção (agnosias). O comprometimento das funções cognitivas é comumente acompanhado, e ocasionalmente precedido, por deterioração do controle emocional, comportamento social ou motivação. A demência produz um declínio apreciável no funcionamento intelectual e interfere nas atividades da vida diária (AVD), como higiene pessoal, vestimenta, alimentação, atividades fisiológicas.
} 


\section{O envelhecimento no contexto das políticas públicas}

O envelhecimento tornou-se um fato de interesse político e econômico, dado o rápido crescimento demográfico no Brasil e suas implicações para o mercado de trabalho, a previdência social, como também a sua relação com os avanços da ciência. Tendo em vista o aumento considerável da estimativa de vida da população, a chamada "terceira idade" vem configurando-se como sinônimo de envelhecimento ativo e independente que deve ser conquistado por meio da autonomia, dos cuidados com saúde física e mental e da integração nas práticas de sociabilidade, afastando-se o quanto possível da imagem tradicional da velhice, ou seja, aquela ligada à incapacidade física, doenças e senilidade.

$\mathrm{Na}$ última década, a categoria "idoso" foi consolidada pelo estado brasileiro, principalmente a partir do Estatuto do Idoso no qual os indivíduos acima de 60 anos passam a fazer parte de uma parcela da população que tem direitos específicos regidos e legitimados por lei estatutária ${ }^{5}$, bem como presenciamos a criação de políticas públicas relacionadas a práticas de saúde e "prevenção de riscos" para essa população.

A Política Nacional do Idoso, promulgada em 1994 e regulamentada em 1996, assegura direitos sociais à pessoa idosa, criando condições para promover sua autonomia, integração e participação efetiva na sociedade e reafirmando o direito à saúde nos diversos níveis de atendimento do SUS (Lei $\mathrm{n}^{\circ}$ 8.842/94 e Decreto $\mathrm{n}^{\circ}$ 1.948/96). Em 1999, a Portaria n 1.395 anuncia a Política Nacional de Saúde do Idoso (PNSI), a qual determina que os órgãos e entidades responsáveis promovam a elaboração ou a readequação de planos, projetos e atividades na conformidade das diretrizes e responsabilidades nela estabelecidas.

Em 19 de outubro de 2006, o Ministério da Saúde publica a Portaria n ${ }^{\circ} 2.528$ que aprova a Política Nacional de Saúde da Pessoa Idosa. Este documento se propõe a atualizar a política relacionada à saúde do idoso, revisando e revogando as Portarias anteriores (1999 e 2002). O objetivo do governo, de acordo com o documento, é uma maior organização do país para responder às crescentes demandas de sua população que envelhece.

A partir desse momento, o país tem uma política pública que assume a perda da capacidade funcional, ou seja, a perda das habilidades físicas e mentais necessárias para

\footnotetext{
${ }^{5}$ O Estatuto do Idoso foi criado de acordo com a Lei $\mathrm{n}^{\circ} 10.741$, de $1^{\circ}$ de outubro de 2003 . Conta com VII Títulos, entre eles: Dos Direitos Fundamentais, Das Medidas de Proteção, Da Política de Atendimento ao Idoso, Do Acesso à Justiça e Dos Crimes. Cada um deles com uma série de capítulos específicos.
} 
realização de atividades básicas e instrumentais da vida diária ${ }^{6}$ como sendo o principal problema que pode afetar o idoso. Considera, ainda, que a saúde para a população idosa está ligada ao controle e à prevenção de agravos de doenças crônicas nãotransmissíveis, mas não se restringe a isso. Para o PNSI a saúde da pessoa idosa é a interação entre a saúde física, a saúde mental, a independência financeira, a capacidade funcional e o suporte social.

As políticas públicas brasileiras estão inseridas no contexto moderno mais amplo que tem como enfoque principal uma determinada construção da velhice e de como envelhecer. Os velhos passam a ser responsabilizados pelo seu próprio bem-estar nessa fase da vida e as responsabilidades dizem respeito aos cuidados com a saúde (física e psíquica), a participação nas diversas esferas da vida social e a busca de soluções para uma condição financeira confortável.

A abordagem do envelhecimento ativo baseia-se no reconhecimento dos direitos das pessoas idosas e nos princípios de independência, participação, dignidade, assistência e auto-realização determinados pela Organização das Nações Unidas (WHO, 2002). A promoção do envelhecimento ativo, isto é, envelhecer mantendo a capacidade funcional e a autonomia, é reconhecidamente a meta de toda ação de saúde. Ela permeia todas as ações desde o pré-natal até a fase da velhice. Vemos, assim, que o modelo biomédico está presente em todas as fases da vida.

Com a perspectiva de ampliar o conceito de "envelhecimento saudável", em 2005, a Organização Mundial da Saúde (OMS) propõe o "Envelhecimento Ativo: Uma Política de Saúde", ressaltando que os governos, as organizações internacionais e a sociedade civil devem implementar políticas e programas que melhorem a saúde, a participação e a segurança da pessoa idosa.

É a partir desse quadro referente à políticas públicas propostas para o envelhecimento e que estão presentes no cotidiano de homens e mulheres, mais especificamente aqueles envolvidos de alguma forma em programas voltados para "promoção de qualidade de vida" de idosos, que passo a estabelecer relações entre a "construção social da pessoa", o indivíduo como valor básico em nossa cultura moderna ocidental e a noção de "projeto".

\footnotetext{
${ }^{6}$ As atividades básicas da vida diária (AVD) consistem em tomar banho, vestir-se, usar o banheiro, transferir-se da cama para a cadeira, ser continente (urinário), alimentar-se com a própria mão etc. As atividades instrumentais de vida diária (AIVD) correspondem a preparar refeições, controlar a própria medicação, fazer compras, controlar o próprio dinheiro, usar o telefone, fazer pequenas tarefas e reparos domésticos e sair de casa sozinho utilizando um transporte coletivo.
} 


\section{Individualismo, memória e a noção de projeto}

O primeiro texto explícito sobre o que se pode chamar hoje de "construção social da pessoa" é o de Marcel Mauss, publicado em 1938 e intitulado "Uma categoria do espírito humano: a noção de pessoa, a noção do 'eu"” (Mauss, 2003), no qual o autor traz a questão do sujeito moderno - ético, moral, reflexivo - que não seria um sujeito meramente evolutivo. Há um reconhecimento de como as condições e os processos históricos possibilitam a complexificação do sujeito moderno. Assim, haveria uma tridimensionalidade no processo antropológico de compreender o outro, a alteridade. $\mathrm{O}$ autor retoma e amplia a reflexão sobre o pensamento simbólico, trazido anteriormente por Durkheim, abordando a noção humana ligada à tradição e ao projeto de libertação de si (sujeito psíquico). Mauss irá mostrar a tensão entre as formas de pensar o "eu" e o indivíduo, outras formas de interiorização psíquica.

Concomitante a isso, os discípulos treinados pela escola culturalista de Boas e influenciados pelo descentramento do sujeito da psicanálise de Freud, iniciavam nos EUA os primeiros trabalhos do que veio a se chamar em seguida de Escola de Cultura e Personalidade, que também contribuiu para o empreendimento geral de análise comparada das formas de pessoa (Duarte, 2003).

Dumont (1985) avança na discussão ao entender que a noção de hierarquia, na qual toda experiência humana pressupõe uma distribuição diferencial - que é culturalmente definida - do "valor" no mundo, permite justamente a orientação do sujeito em situação. Assim, para a compreensão das experiências culturais em sociedades distintas, como a holista e a individualista, Dumont (1985) traçou a oposição entre as ordens tradicionais de construção da "pessoa" - definidas como um processo relacional de disposições de sistemas e socialmente determinadas -, e o modelo moderno do "indivíduo" - com sua aspiração a liberdade, igualdade, autonomia, autodeterminação e singularidade. Desse modo, teríamos em nossa sociedade o modelo pautado pela ideologia do individualismo, na qual o valor fundante é o indivíduo.

Nessa perspectiva, a contribuição de Giddens no tocante ao "projeto reflexivo do eu" mostra a abertura de um leque de possibilidades, diversidade e escolhas para o indivíduo. Ele passa a ser responsável por si mesmo e o planejamento estratégico da sua vida assume maior importância. Para Giddens (1991, p.43) "a reflexividade é uma característica definidora de toda ação humana. Todos os seres humanos rotineiramente 'se mantém em contato' com as bases do que fazem como parte integrante do fazer'. Essa noção de reflexividade social diz respeito a uma sociedade na qual as condições 
em que os indivíduos vivem são cada vez mais o resultado de suas próprias ações, e, inversamente, essas ações vivem cada vez mais a administrar ou enfrentar os riscos e oportunidades criadas por eles mesmos. Nesse sentido, a modernidade é constituída pelo conhecimento reflexivamente aplicado.

O projeto de um envelhecimento "moderno", "novo", "ativo", "saudável” e, principalmente, "autônomo" torna-se, assim, visível nesses corpos. E com tantos aparatos sociais disponíveis, leva-se a crer que, se a velhice não for bem-sucedida foi por incapacidade do próprio indivíduo (Barros, 2004).

De acordo com Velho (1994), nas sociedades onde predominam as ideologias individualistas, as trajetórias dos indivíduos passam a significar elementos constituidores da própria sociedade. A memória do indivíduo torna-se fundamental e mais relevante socialmente. "Suas experiências pessoais, seus amores, desejos, sofrimentos, decepções, frustrações, traumas, triunfos etc. são os marcos que indicam o sentido de sua singularidade enquanto indivíduo" (Velho, 1994: 100). E noções como, por exemplo, carreira, biografia e trajetória começam a fazer sentido e a transformar progressivamente o indivíduo biológico em valor básico da sociedade ocidental moderna.

Para o autor, a noção de "projeto" está indissoluvelmente imbricada à idéia de indivíduo-sujeito, pois o indivíduo-sujeito é aquele que faz "projetos". A noção de "projeto" a qual fala Gilberto Velho foi desenvolvida por Alfred Schutz (1979) que a caracteriza como sendo a "conduta organizada para atingir finalidades específicas". Schutz irá analisar como o indivíduo movimenta-se na esfera pública orientado por aspectos simbólicos, como agir diante das múltiplas alteridades e a partir da teia de significados culturais e como se conformam as fronteiras simbólicas no espaço e no tempo. Para isso, o autor traz alguns pontos da obra de Husserl como, por exemplo, a noção de intencionalidade, tendo em vista que a consciência apenas existe quando endereçada a um objeto e este sempre é um objeto para alguém, ou seja, a consciência é sempre consciência de alguma coisa e a intencionalidade é este direcionamento da consciência a um objeto. Assim, Schutz propõe pensar sobre "os motivos afim de", ou seja, as motivações, as constelações de interesses, os planos de ação, os projetos dos indivíduos.

Para Velho (1994), em sua análise sobre Schutz, a memória tem significado fundamental, pois é ela que assegura a consistência da biografia do indivíduo, possibilitando, assim, a formulação e condução de projetos. A durée faz com que 
apareça na consciência uma sobreposição de situações, de um cotidiano sempre presente, de uma "imediatez" da consciência e da experiência. (...) é no tempo interior, ou na durée, que nossas experiências atuais são ligadas ao passado por meio de lembranças e retenções e ao futuro por meio de protensões e antecipações (Schutz, 1979: 69).

Os significados das experiências são produzidos biograficamente em um mundo vivido coletivamente e que tem um caráter prático. O sujeito vivencia o cotidiano do presente imediato, embora ele, enquanto estiver na situação, não esteja consciente disto. Esta situação parece sempre irreversível àquele que a está vivenciando. Schutz (1979) revela, portanto, que a importância do significado é dada pela experiência passada que a pessoa possui sobre um fato. Isto faz com que o significado das ações seja dado em consonância com as suas experiências anteriores. Entendendo, todavia, que a memória é fragmentada e o passado é marcado por descontinuidades e rupturas.

Assim, "memória" e "projeto" estão associados e articulam-se para dar significado a vida e as ações dos indivíduos em sociedade. É importante ressaltar ainda que o "projeto" só existe na intersubjetividade, ele é um instrumento de "negociação da realidade" com diferentes atores, sejam eles individuais ou coletivos, bem como é um posicionamento do "eu" no mundo, a partir de um "campo de possibilidades" em que está inserido o sujeito.

\section{Sociabilidade e narrativas de idosos na reconstituição das durações de seus tempos vividos}

No que se refere à sociabilidade, trago para essa discussão o pensamento de Simmel (1979; 2006). Para o autor, a própria sociedade significa a interação entre os indivíduos. Porém, a interação irá surgir a partir de determinados impulsos ou da busca de certas finalidades individuais. Em outras palavras, os impulsos, os interesses, as finalidades, as tendências, as motivações existem nos indivíduos e geram fatores de sociação (por exemplo, a fome, o amor, o trabalho, a religiosidade etc) apenas "quando transformam a mera agregação isolada dos indivíduos em determinadas formas de estar com o outro e de ser para o outro" (Simmel, 2006: 60). Assim, é possível observarmos a dimensão individual percebida por Simmel nos fatores de sociação no contexto interacional. Para o autor, a sociação seria: 
[...] a forma (que se realiza de inúmeras maneiras distintas) na qual os indivíduos, em razão dos seus interesses - sensoriais, ideais, momentâneos, duradouros, conscientes, inconscientes, movidos pela causalidade ou teologicamente determinados -, se desenvolvem conjuntamente em direção a uma unidade no seio da qual esses interesses se realizam. (Simmel, 2006, p.60-61)

Para uma compreensão mais elucidativa do modo como se organiza a sociedade através de uma associação básica, temos o conceito de "sociabilidade". De acordo com Simmel, um tipo ideal entendido como o "social puro", onde há ações de reciprocidade consciente entre os indivíduos, uma forma lúdica arquetípica de toda a socialização humana, na qual os propósitos, interesses ou objetivos dizem respeito à interação em si mesma, vivida em espécie de jogos, nos quais uma das regras implícitas seria atuar como se todos fossem iguais (Frugoli, 2007: 9). Simmel apresenta como exemplos a coquetterie e a conversação.

Frugoli (2007), ao traçar considerações sobre o conceito de sociabilidade, mostra que ele foi relido (ou re-significado) pela Escola de Chicago, pioneira na prática etnográfica voltada ao contexto urbano. Com o advento da Escola de Chicago a conceito de sociabilidade teria adquirido uma abordagem eminentemente empírica, tendo em vista que foi a primeira a tomar a cidade como laboratório de análise da mudança social e a formular uma concepção espacializada do social e, reciprocamente, uma concepção socializada no espaço.

Entre os vários usos e significados do conceito de sociabilidade ao longo do século XX, uma série de autores trabalharam essa temática em suas pesquisas. Frugoli (2007) apresenta alguns desses trabalhos e divide as possíveis abordagens do tema em dois momentos: numa primeira leitura as formas de sociabilidade são tomadas como possibilidades de construção temporária do próprio social entre estranhos ou atores sociais de condições diversas, nessa abordagem a interação em si constituiria o principal intuito. Numa segunda leitura, o tema da sociabilidade traz uma qualidade "intraclassista", onde as relações seriam praticadas principalmente entre iguais na articulação entre "sociabilidade", "vizinhança" ou "comunidade".

É nesse sentido que proponho pensar os encontros do grupo de idosos no posto de saúde da Vila Jardim. Sair de casa as sextas-feiras pela manhã para encontrar vizinhos e amigos no posto de saúde do bairro é a forma de sociabilidade escolhida por cerca de quinze idosos, a maioria mulheres, por mais de dez anos. O número de 
participantes tem variado ao longo desse tempo ${ }^{7}$ e a freqüência segue o ritmo das estações do ano, dos dias ensolarados ou chuvosos e das eventuais doenças que impossibilitem a caminhada até o posto.

Nos últimos quatro meses, também as sextas-feiras, por volta de 8 horas da manhã, saio do Centro de Porto Alegre em direção ao bairro Vila Jardim, na Zona Norte da cidade. Desço do ônibus na Av. Saturnino de Brito e continuo o percurso a pé rumo ao posto de saúde. $\mathrm{Na}$ subida da rua de lindas casas e condomínios vejo algumas entradas que possivelmente levam aos tantos becos existentes no bairro. No ponto mais alto da rua, olho para o lado direito e admiro a bela vista de árvores e prédios ao longe.

Imagino que há anos atrás eram aqui, nesse local por onde caminho hoje, os "descampados" e terrenos desocupados onde as crianças brincavam sob os olhos das mulheres da vizinhança e as famílias menos favorecidas ("posseiros") tentavam construir suas casas, como vemos nos trabalhos de Giacomazzi (1997) e Victora (1991). As autoras chamam atenção para as intensas transformações que estavam ocorrendo na paisagem urbana do bairro naquele momento.

É possível observar que o bairro passou de uma área de ocupação - onde uma população desfavorecida financeiramente construiu pequenas casas em becos e ruas pouco habitadas - para uma área de especulação imobiliária, com a construção de avenidas, shopping center e demais empreendimentos comerciais, grandes casas e condomínios. Uma das recentes construções é a casa da ex-governadora do Rio Grande do Sul, Yeda Crusius. Para alguém de fora daquele "pedaço", um visitante em suas primeiras caminhadas pelas principais ruas do bairro, provavelmente não enxergará à primeira vista as inúmeras diferenças entre os moradores, as residências e os estilos de vida dos que habitam essa área da zona norte da cidade.

Após caminhar algumas quadras, chego às dependências do posto de saúde. Como mencionei anteriormente, em praticamente todos os encontros ouvi referências a respeito da luta de pessoas da comunidade, inclusive algumas delas são participantes do grupo de idosos, para a conquista do terreno e a construção do prédio onde está localizado o posto atualmente. Além da ampla área externa, o posto tem uma recepção para agendamento e espera de consultas, consultórios médicos, ambulatório, banheiros, pequenas salas para outros profissionais como a assistente social e os estagiários de nutrição, cozinha, associação comunitária Vovó Nair e uma sala grande que reúne os

\footnotetext{
${ }^{7} \mathrm{Na}$ lista de participantes e freqüência registrada pela assistente social nos últimos dois anos constam mais de trinta idosos.
} 
grupos como, por exemplo, o grupo de idosos, de mulheres, de hipertensos e diabéticos, de pilates (para reabilitação de doenças ósseas, especialmente na coluna cervical), grupo de pessoas com deficiência cognitiva, bem como as reuniões dos profissionais de saúde. Nesta sala encontramos uma mesa com uma televisão de 29', um computador, cartazes informativos, um mural com fotos, uma maquete das áreas atendidas pelo posto (com as "zonas de vigilância" marcadas em cores fortes), um espelho grande na parede, uma mesa, várias cadeiras dispostas em círculo e uma porta larga que dá acesso a parte lateral do posto.

Conversando com uma médica ginecologista que trabalhava acompanhou ativamente a construção do posto passando, em seguida, a trabalhar nessa unidade, soube que em 1991 a comunidade solicitou junto ao GHC um outro posto de saúde para o bairro. Como o GHC não tinha sede própria, alugou, no ano seguinte, um galpão onde funcionava uma fábrica de sabão. A comunidade construiu alguns consultórios, outros foram improvisados e a equipe médica começou a atender nesse local. Em 2000, a comunidade ganha o terreno da empresa privada Condor e faz a doação para o GHC que inicia as obras com a fiscalização diária dos moradores do bairro. A obra é encerrada em 2002 e o posto muda-se para o novo endereço.

O grupo de idosos e o grupo de mulheres são os mais antigos no posto, iniciados ainda no antigo endereço por solicitação das algumas mulheres da comunidade que queriam um espaço para o lazer, "para conversar", "sair um pouco de casa". Devido, provavelmente, a proximidade afetiva dos usuários com o posto e o sentimento de pertencimento com esse local, ele foi escolhido para abrigar também a dimensão lúdica de algumas moradoras mais velhas da vila.

Com o apoio de uma médica e uma técnica em enfermagem esses encontros tornaram-se freqüentes e além das conversas, elas iniciaram os bingos e chás. A prioridade das participantes não eram as questões de saúde e sim a sociabilidade, contudo a médica e a técnica em enfermagem decidiram que as reuniões passariam a ter um momento para orientações de saúde relacionadas a quedas, diabetes, hipertensão etc. Com a chegada da assistente social, o grupo continuou se encontrando sob sua coordenação. Além das discussões sobre saúde terem se tornado mais intensas, os bingos, chás e também viagens para eventos em outras cidades realizavam-se com mais assiduidade e com a participação de um número maior de idosos. Há alguns anos, a assistente social transferiu-se para outra unidade de saúde e o grupo permaneceu ativo mesmo sem alguém que o "coordenasse". Em 2008, a nova assistente social assume as 
atividades com os demais profissionais de saúde, agora sob uma perspectiva mais sistemática e pautada nas diretrizes da promoção de qualidade de vida e do envelhecimento saudável.

De acordo com Eckert e Rocha (2001: 4), “é através do estudo dos itinerários urbanos e das formas de sociabilidade, das intrigas e dos dramas que configuram o teatro da vida citadina, apreendidos como uma espécie de mapeamento simbólico do movimento da vida que se pode, nos dias de hoje, refletir sobre a complexidade sociológica das estruturas espaço-temporais sob as quais se assentam os fenômenos da alteridade e da experiência humana no mundo contemporâneo".

Refletir sobre as formas de vida social no meio urbano convoca o antropólogo a voltar-se para na sua própria sociedade na tentativa de entender seus próprios sistemas de classificação. Como procurei mostrar ao longo deste texto, o campo conceitual da disciplina percorreu um longo caminho, reconhecendo que o fenômeno urbano é o resultado da ação recíproca de indivíduos e de grupos. Estudar as formas específicas dos arranjos da vida social, levando em conta a complexidade das "trajetórias" e da "memória" de seus habitantes, possibilita "a compreensão do processo de territorialização/desterritorialização de identidades sociais no mundo contemporâneo", bem como "o entendimento da descontinuidade/continuidade sistêmica de valores acionados, de redes/espaços sociais que situacionam os sujeitos segundo suas trajetórias, posições e papéis, suas adesões e suas dissidências no contexto citadino" (Eckert e Rocha, 2001: 4).

Nos encontros do grupo de idosos, observo que algumas questões são recorrentes como as conversas sobre os filhos, a vizinhança, as doenças e a morte de parentes ou conhecidos. Independente do tema escolhido pela equipe para ser discutido no encontro, em algum momento essas questões são comentadas por alguém do grupo e inicia-se uma conversa paralela sobre esses aspectos da vida cotidiana dos idosos.

Cada memória individual é um ponto de vista da memória coletiva e esse ponto de vista varia de acordo com o lugar social ocupado pelo indivíduo. A memória é uma construção social e o ato de rememorar torna-se possível a partir dos "quadros sociais da memória", ou seja, pelos espaços, sons, cheiros e sabores que servem como pontos de referência. Halbwachs (2006) não institui tais espaços apenas no sentido físico, mas também, como lugar simbólico. Para ele, as imagens que ficam dentro desses quadros sociais são as lembranças que, por sua vez, têm um significado, uma marca para aquele que lembra, contém um conteúdo simbólico. Vale salientar que esses quadros sociais 
estão interligados ao tempo, sendo o tempo concebido como sendo descontínuo e com rupturas, um tempo vivido que é narrado por homens e mulheres e definido com suas marcas.

A partir de lembranças sobre a vinda da cidade do interior para Porto Alegre, a chegada no bairro, o trabalho, a criação e educação dos filhos, o casamento, a morte do marido ou familiar, a experiência da doença - seja como doente ou cuidador -, a participação na construção do posto vão organizando um todo repleto de significados. Por outro lado, é interessante perceber como a Cidade, em sua polissemia, torna-se também o testemunho desses jogos da memória. Como nos lembra Eckert e Rocha (2001: 8), a Cidade é o "espaço fantástico onde eles podem "colar" sua existência a certos momentos de interação social vividos em seus territórios e investi-los do próprio ritmo construído no corpo da duração de biografias de vida”.

A chegada da família na cidade e no bairro, bem como a criação dos filhos em Porto Alegre e na Vila Jardim está presente nas narrativas da maioria dos idosos do grupo. Um senhor de sessenta e cinco anos que mora com duas filhas num dos becos da Rua Israel, contou-me mais de uma vez sobre a sua vinda com a esposa para a Vila Jardim: "Eu vi que aqui era um bairro bom, tinha uns terrenos desocupados e eu vim olhar, depois eu disse [para a esposa]: 'é aqui que a gente vai morar, nós vamos pegar um terreno desse e construir nossa casa"'. Em outro momento, relembra como eles trabalharam muito, às vezes em mais de um emprego, para conseguir criar bem os três filhos apesar de morar em um local que durante alguns anos foi considerado perigoso e marginalizado:

\footnotetext{
Eu criei meus três filhos aqui, o guri casou e não mora mais comigo, as duas gurias moram, elas cuidam muito de mim, sempre ligam do serviço durante o dia e perguntam 'tudo bem por aí, velho?', 'como é que tu tá, velho?'. Meus filhos são muito bons, tive muita sorte, formei dois e, se Deus quiser, vou formar a mais nova agora em Direito igual o irmão dela, ela está indo nos passos do irmão, já a outra é fonoaudióloga, meus filhos todos são boas pessoas, trabalham o dia inteiro, as gurias só chegam em casa de noite para tomar um banho, comer alguma coisa e dormir e no outro dia bem cedo começar tudo de novo, né? (...) e eu fico pensando que eu formei os três ali na Israel, sabe a Israel, né?.
}

Além dos encontros semanais no posto, a equipe de profissionais e uma das participantes do grupo organizam passeios para locais em Porto Alegre como museus e, principalmente, para outras cidades como Santa Cruz do Sul no mês de outubro por ocasião da Oktoberfest e para cidades de Santa Catarina e do Rio Grande do Sul que oferecem hotéis com piscinas naturais de águas termais. 
No dia 13 de outubro de 2010 acompanhei o grupo para o município de Santa Cruz do Sul. A programação da Oktoberfest neste dia destinava-se a "Maturidade Ativa", então o grupo do posto e tantos outros grupos de idosos de todo o estado organizaram-se para participar do evento. Um ônibus alugado saiu pouco antes das $9 \mathrm{~h}$ da manhã do posto com trinta de sete idosos, cinco profissionais de saúde da unidade e eu, totalizante quarenta e três pessoas. Como a viagem durou o dia inteiro (retornamos por volta de 20h), houve muitas conversas no ônibus, paradas para lanches e utilização de banheiros, o almoço num restaurante em Santa Cruz e os passeios pelo parque da Oktoberfest que ocorreram durante à tarde.

Após a entrada no parque nos dividimos em grupos de três a cinco pessoas para facilitar o deslocamento pelo parque e o acompanhamento dos idosos. Fiquei com um pequeno grupo de mulheres que freqüentemente converso nas reuniões do posto. Num dos momentos de descanso - uma pausa para sentar, tomar água e sorvete, pois a tarde de primavera estava quente e já havíamos andado por toda parte olhando flores, feira de artesanato e comprado cucas e salames nas bancas de alimentação - uma das senhoras de oitenta e cinco anos, nascida em Bento Gonçalves, pergunta se estou gostando de morar no Rio Grande do Sul, porque escolhi mudar de cidade e sobre o meu trabalho. Antes que eu responda todas as perguntas, ela começa a contar sobre a sua mudança para Porto Alegre. Em meio ao barulho das bandinhas de música e das conversas das pessoas que se apertavam para conseguir um lugar para sentar, ela conta que mudou de cidade com o marido e os quatros filhos pequenos há muitos anos, pois sua filha mais nova era muito pequena nessa época e hoje está com mais de cinqüenta anos.

\begin{abstract}
Meu marido disse que não ficava mais lá, que se eu quisesse podia ficar, mas que ele vinha embora para tentar coisa melhor por aqui. Então, a gente veio tudo com os quatro filhos. Aqui tem muito mais oportunidades, né? Foi uma boa coisa essa que fizemos, pois nossos filhos estudaram, lá não tinha nada de estudo e também não tinha trabalho. Foi uma pena meu marido ter morrido antes de ver os filhos crescerem na vida, quando ele morreu eles não estavam tão bem como estão agora. Os rapazes casaram e as moças não quiseram nunca casar e moram comigo até hoje [sorri e pergunta como é o casamento lá de onde eu venho, se as pessoas querem casar]. E foi assim, cada um foi trabalhando numa coisa, mas às vezes não gostava ou não dava certo. Até que uma das minhas filhas foi trabalhar numa imobiliária e viu que imobiliária era bom, dava dinheiro, aí ela falou para os irmãos e ela junto com outro resolveram abrir uma imobiliária deles, depois os outros dois foram trabalhar lá também. Cada um foi vendo que dava certo e foi entrando também. Eles trabalham tudo junto e isso é muito bom.
\end{abstract}

A partir desses fragmentos reorganizados no ato da narrativa, é possível compreender como os indivíduos e os grupos produzem e transmitem conjuntos de 
significados sobre os territórios urbanos em que habitam. O "viver a cidade" é parte fundamental da construção de um tempo coletivo urbano. Assim, a Cidade é "restituída a sua função primeira: cenário da anamnese de sua comunidade, pois em seus espaços emergem as lembranças e signos das representações culturais de seus habitantes, onde o jogo das origens não tem fim, não se submete à ordem e à classificação dos signos" (Eckert e Rocha, 2001: 13).

Quando o assunto nos encontros diz respeito à participação na comunidade e a construção do posto, cada um tem uma história para contar sobre tijolos, uma porta ou maçaneta que compraram e levaram até a obra, bem como a visita aos estabelecimentos comerciais do bairro em busca de doações de material de construção. Pode-se perceber, a partir dessas narrativas, um forte sentimento de pertencimento e um orgulho de ser morador do bairro. Assim, além de falarem sobre o que fizeram pessoalmente durante todo esse processo, narram também a participação dos outros moradores da comunidade. Fragmentos das trajetórias do grupo vão surgindo e possibilitando a ordenação do mosaico de relações sociais, reciprocidade e sentidos atribuídos aquele espaço. Uma das personagens principais é Vovó Nair, considerada uma liderança da comunidade, inclusive sendo homenageada pela associação comunitária do bairro que recebeu seu nome. Ela esteve à frente da fundação e atividades da associação por muitos anos como, por exemplo, atividades assistenciais e mobilizações para melhorias relacionadas à infraestrutura na comunidade, também participou ativamente das negociações para conseguir o terreno e de todo o processo que culminou na construção da nova sede do posto.

Nos últimos meses as lembranças a respeito de sua trajetória de luta ficaram mais recorrentes. Há cerca de dois anos Nair começou a apresentar sintomas da doença de Alzheimer e em 2010 houve um rápido avanço da doença que a afastou de todas as atividades as quais ela participava na comunidade, inclusive o grupo de idosos e a presidência da associação comunitária.

A doença de Alzheimer está ligada, entre outras coisas, a perda de autonomia do indivíduo e também ao conceito de "pessoa", tendo em vista que os comportamentos da pessoa acometida pela doente são muitas vezes percebidos como não sendo "dela". Em diversos casos, como os citados no trabalho de Leibing (1999), a partir de um determinado momento a doença se manifesta despercebida e quando parentes e amigos relembram os acontecimentos, quando "olham para trás", vêem que já não se tratava 
mais da pessoa em sua "verdadeira essência", ou seja, ela havia se tornado uma nãopessoa.

Pode-se perceber uma dificuldade, principalmente na fase inicial da DA, de reconhecer ou mesmo aceitar que o indivíduo está adoecendo. Por ora, não pretendo analisar os sintomas e possíveis causas atribuídas ao desenvolvimento desta doença ${ }^{8}$, o interessante é pensar a questão da autonomia que está relacionada a esse processo. Segundo Doll e Karl (2006), a perspectiva potencial da perda do controle cognitivo atinge o ser humano atualmente em um dos fundamentos da "modernidade reflexiva", na obrigação de supervisionar permanentemente sua vida através da auto-reflexividade.

O indivíduo, ator consciente no mundo moderno, precisa dar conta dos diferentes aspectos da realidade social através de um esforço intelectual próprio. Isso se apresenta diferente no caso da demência. O projeto de autonomia (capacidade de decidir sobre seus objetivos pessoais), bem como o de independência (capacidade de realizar tais objetivos sozinhos), ou seja, as questões fundamentais da proposta da "qualidade de vida" da pessoa idosa e de um envelhecimento saudável tornam-se inviabilizadas. $\mathrm{Na}$ experiência atual do envelhecimento pautada pela autonomia e independência, o indivíduo se depara com uma situação de doença que vai justamente ao contrário disso, causando diversas sensações adversas naqueles que convivem com alguém acometido pela DA, inclusive o sentimento de impotência diante de uma doença que ainda não pode ser curada.

Nos momentos de sociabilidade do grupo existe a tentativa de organizar o caos e a desordem interior e exterior instaurado pela doença e essa reorganização passa pela reconstituição da "pessoa" naquele indivíduo, lembrar quem ela era, o seu trabalho de liderança na comunidade.

No mês de agosto, na ocasião do encontro destinado ao "dia da saúde", observei que enquanto a enfermeira e os estagiários de nutrição faziam os procedimentos de medir pressão arterial, glicose, peso e altura, as quatro mulheres e o homem que estavam na sala conversavam sobre o cotidiano, contando as novidades sobre os familiares, os vizinhos, alguém do grupo que ficou doente ou que há tempos não aparece, relatando alguma dor ou falando sobre os medicamentos que o médico receitou na última consulta. Uma das participantes do grupo de oitenta e quatro anos que em vários encontros havia falado sobre a doença de Alzheimer de seu marido e de seu papel

\footnotetext{
${ }^{8}$ Ver Leibing, 1999.
} 
de cuidadora durante cinco anos voltou a comentar sobre o assunto enquanto aguardava ser chamada para aferir sua pressão arterial:

\footnotetext{
Ele não lembrava mais de ninguém, às vezes nem de mim, é uma coisa muito triste, a gente casado mais de cinquienta anos e ele não me reconhecia, nem os filhos ele também não sabia mais, ele só falava de morto, só morto, aquilo me dava medo, mas era porque ele só lembrava de gente da infância dele que já estavam mortos, né? Essa é uma doença muito triste, vai acabando com a pessoa aos poucos, não o físico, porque ele não tinha nada, mas o negócio é a cabeça da pessoa. Ele não podia ficar sozinho um minuto e eu cuidei dele o tempo inteiro até ele morrer. (...) É, menina, a gente paga caro para envelhecer.
}

Antes de falecer, seu marido começou a fazer hemodiálise e, em seguida, morreu por conta de um acidente vascular cerebral (AVC). Depois que ele foi acometido pela DA, há mais de doze anos, ela conta que iniciou inúmeros tratamentos psicológicos e psiquiátricos.

\section{Considerações finais}

Neste artigo busquei refletir sobre a articulação entre conceitos caros para a antropologia como envelhecimento, individualismo, memória, "projeto" e sociabilidade. De acordo com o que foi abordado ao longo do texto, é possível perceber que os idosos devem assegurar sua capacidade de autopercepção através de condições psíquicas razoáveis, como também, manterem-se independentes fisicamente para garantir seu lugar social como indivíduos numa sociedade de indivíduos. Para conseguir cumprir esta proposta surgem as inúmeras atividades de lazer, os espaços de sociabilidade, os cuidados corporais, a preocupação com o sistema de previdência e a aposentadoria e, consequentemente, a valorização da participação do idoso nas diversas esferas sociais.

Por fim, trago as considerações de Eckert e Rocha (2001: 11) sobre o exercício fundamental de "dar conta desta dinâmica da continuidade/descontinuidade de universos simbólicos, em que grupos/indivíduos co-dividem, num mesmo espaço, relações extremamente diversas, muitas delas de forma mais isolada, outros se reagrupando em associações, outros ainda interagindo em redes mais ou menos informais, de qualquer maneira sempre dimensionando sistemas de valores, de imagens, de códigos, formas de pensar e exprimir-se diferencialmente".

Recuperar as trajetórias sociais e o cotidiano através do trabalho da memória possibilita o acesso a instantes privilegiados, onde os idosos podem reconstituir as durações de seus tempos vividos através das narrativas, como também a partir de 
rupturas, dramas e mesmo do "caos" re-organizar a vida, tecendo um conhecimento sobre si mesmo e sobre o mundo.

\section{Referências}

BACHELARD, Gastón. A dialética da duração São Paulo: Ática, 1988.

BARROS, Myriam Lins de. "Testemunho de vida: um estudo antropológico de mulheres na velhice". In: Perspectivas antropológicas da mulher 2. Rio de Janeiro: Zahar, 1981. p.11-70.

BARROS, Myriam Lins de. Autoridade e afeto: avós, filhos e netos na família brasileira. Rio de Janeiro: Zahar Editores, 1987.

BARROS, Myriam Lins de. "Memória de velhos e família". In: Revista Estudos históricos, v.2, n.3. Rio de Janeiro: CPDOC/FGV, 1989. p.29-42.

BARROS, Myriam Morais Lins. "Velhice na contemporaneidade". In: PEIXOTO, Clarice Ehlers (org.). Família e envelhecimento. Rio de Janeiro: Editora FGV, 2004.

BENJAMIM, Walter. "Sobre alguns temas em Baudelaire". In: Obras escolhidas III:

Charles Baudelaire um lírico no auge do capitalismo, 4.ed. São Paulo: Ed. Brasiliense, 2004.

BERGSON, Henri. Matéria e memória. Ensaio sobre a relação do corpo com o espírito. São Paulo: Martins Fontes, 1990.

BRASIL. Ministério da Saúde. Estatuto do Idoso / Ministério da Saúde. - 1. ${ }^{a}$ ed. 2. ${ }^{a}$ reimpressão. Brasília: Ministério da Saúde, 2003.

DOLL, Johannes, KARL, Fred. "Demência e pedagogia social". In: Estudos interdisciplinares sobre o envelhecimento, v. 10. Porto Alegre: PROREXT/UFRGS, 2006. p. 45-56.

DUARTE, L. F. D. "Indivíduo e pessoa na experiência da saúde e da doença". In: Ciência e saúde coletiva, v.8, n.1. Rio de Janeiro: Associação Brasileira de PósGraduação em Saúde Coletiva, 2003. p.173-183.

DUMONT, Louis. $O$ individualismo. Uma perspectiva antropológica da ideologia moderna. Rio de Janeiro: Rocco, 1985.

ECKERT, C., ROCHA, A. L. Carvalho da. "Premissas para o estudo da memória coletiva no mundo urbano contemporâneo sob a ótica dos itinerários de grupos urbanos e suas formas de sociabilidade". In: Revista Iluminuras, v. 2, n. 4. Porto Alegre: BIEV/UFRGS, 2001. Disponível em: http://www.seer.ufrgs.br/index.php/iluminuras/article/view/9122

FRUGOLI, Heitor Jr. Sociabilidade urbana, (Coleção Passo-a-Passo; 80). Rio de Janeiro: Zahar, 2007.

GIACOMAZZI, Maria Cristina Gonçalves. O cotidiano da Vila Jardim: um estudo de trajetórias, narrativas biográficas e sociabilidades, sob o prisma do medo na cidade Porto Alegre (RS). Tese de Doutorado em Antropologia Social, TOMO I. Porto Alegre: UFRGS, 1997.348 p.

GIDDENS, Anthony. As conseqüências da modernidade. São Paulo: Editora UNESP, 1991.

HALBWACHS, Maurice. A memória coletiva. São Paulo: Centauro Editora, 2006.

LEIBING, Annette. "Olhando para trás: os dois nascimentos da doença de Alzheimer e a senilidade no Brasil". In: Estudos interdisciplinares sobre o envelhecimento, v. 1. Porto Alegre: PROREXT/UFRGS, 1999. p. 37-56. 
MAUSS, Marcel. Sociologia e antropologia. São Paulo: Cosac \& Naify, 2003.

SIMMEL, G. "A metrópole e a vida mental". In: VELHO, Otávio G. (org). O fenômeno urbana. Rio de Janeiro: Zahar, 1979. p 11-25.

SIMMEL, G. Questões fundamentais da sociologia: indivíduo e sociedade. Rio de Janeiro: Jorge Zahar Ed., 2006.

VELHO, Gilberto. Individualismo e cultura. Notas para uma antropologia da sociedade contemporânea. Rio de Janeiro: Zahar, 1981.

VELHO, Gilberto. Subjetividade e sociedade, uma experiência de geração. Rio de Janeiro: Zahar, 1986.

VICTORA, Ceres Gomes. Mulher, Sexualidade e Reprodução: Representações de Corpo em uma Vila de Classes Populares em Porto Alegre. Dissertação de Mestrado em Antropologia Social. Porto Alegre: UFRGS, 1991. 203 p.

WAGNER, Helmut R. (Org.). Fenomenologia e relações sociais. Textos escolhidos de Alfred Schutz. Rio de Janeiro: Zahar, 1979.

WORLD HEALTH ORGANIZATION - WHO. The world health report 2002: reducing risks, promoting healthy life. Genebra, Suiça, 2002. 